\title{
Editorial
}

https://doi.org/10.11646/megataxa.1.2.4

http://zoobank.org/urn:lsid:zoobank.org:pub:CC85771A-2195-4BDC-AB3F-2384922F208C

\section{Promoting excellence of monographs in taxonomy}

\author{
ZHI-QIANG ZHANG ${ }^{1,2}$ \\ ${ }^{I}$ Manaaki Whenua-Landcare Research, 231 Morrin Road, Auckland, New Zealand; \\ !"zhangz@landcareresearch.co.nz; 이ttps://orcid.org/0000-0003-4172-0592 \\ ${ }^{2}$ Centre for Biodiversity \& Biosecurity, School of Biological Sciences, University of Auckland, Auckland, New Zealand
}

Megataxa was designed mainly for large monographic reviews and highly significant original papers reporting major advances in taxonomy (Zhang 2020). Monographs, being comprehensive treatments of various taxa, are the most important works in taxonomy. They are extremely important to understanding biodiversity, but they require so much expertise and efforts that they are rarely attempted by many taxonomists these days (Muñoz-Rodríguez et al. 2019). In Zootaxa and Phytotaxa, monographs are operationally categorized as large papers of 60 or more printed pages. Last year, Zootaxa published 118 such monographs (or about ten each month), whereas Phytotaxa published ten in total (Table 1), although Phytotaxa published $38 \%$ as many papers as Zootaxa in that year. The rate of open access for Zootaxa monographs is 11\% in 2019, whereas that for Phytotaxa is zero. This pattern is more or less the same in 2020 based on the data from the first three quarters. We therefore expect that most of the contributions to Megataxa will come from zoologists. Megataxa, aimed to be a premium journal in taxonomy, differs from Zootaxa and Phytotaxa in that it sets a higher requirement for monographs: a minimum length of 200 printed pages; only $7.8 \%$ of the monographs published in Zootaxa during 2019 and 2020 meet this requirement.

It is my great delight to announce the publication of the first monograph in Megataxa on 80 species of mygalomorph spiders of the genus Actinopus (Miglio et al. 2020). This monograph was originally submitted to Zootaxa and edited by Dr Robert Raven.

Mygalomorph spiders are unequivocally difficult spiders taxonomically: many are depauperate of easily recognizable characters which often show spectacular bilateral variability and serious sexual dimorphism. Thus, recently more energy has been directed at molecular methods to help resolve relationships and matching sexes but the taxon sampling in that discipline is still very young and diversity is being lost. Thus, spider taxonomists still rely heavily on morphospecies concepts. Equally, many countries are understandably resistant to posting types. Thankfully, stereomicroscope imaging and scanning electron microscopy are now much more readily available. Thus, the imperative is that descriptions and associated images are of the highest standards.

One of the reviewers, Dr Jeremy Wilson of

TABLE 1. Monographs (60 or more printed pages) in Zootaxa and Phytotaxa in 2019 and 2020.

\begin{tabular}{lcc}
\hline $\mathbf{2 0 1 9}$ & Zootaxa & Phytotaxa \\
Number of monographs (per year) & 118 & 10 \\
$\quad$ Rate of open access (\%) & 11 & 0 \\
Number of monographs (per month) & 9.8 & 0.8 \\
Average size (number of pages) & 112 & 110 \\
The largest monograph & 619 & 215 \\
$\mathbf{2 0 2 0}$ & & 7 \\
Number of monographs (per year) & 125 & 0 \\
Rate of open access (\%) & 12 & 0.6 \\
Number of monographs (per month) & 10.4 & 259 \\
Average size (number of pages) & 113 & 656 \\
The largest monograph & 668 & \\
\hline
\end{tabular}

\footnotetext{
* Based on data of the first three quarters (Jan. to Sept.).
} 
Argentina, commented: "This taxonomic revision is magnificent, and will serve as the foundation of all future work on Actinopus". In accepting this monograph for publication, Dr Raven wrote: "This amazing monograph by Laura Miglio and coauthors revised the very strange mygalomorph genus Actinopus in South America. In comparison to Missulena, its Australian sister genus, it shows remarkable morphological diversity both somatically and in the usually conservative male pedipalps. The authors have spectacularly noted and extremely well described the many characters that define the species and the genus. All of the detail provided is of the highest quality and significance and richly endowed with an important data on the burrow. The descriptions are highly consistent and thus eminently comparable and useful for molecular, cladistic and DELTA keys; they will sorely test questions played out from molecular analyses. The authors have plumbed the depth of the genus and revealed what I call its language, the characters that distinguish the species. Unequivocally, this is a paper which will stand forever as the highest standard of mygalomorph taxonomy contrasting so spectacularly against my own".

\section{Acknowledgments}

I thank Dr Robert Raven for his excellent editorship as well as his assistance in transferring this monograph from Zootaxa to Megataxa. I also thank Prof Mark Costello for reviewing the draft of this editorial and his comments.

\section{References}

Miglio, L., Pérez-Miles, F. \& Bonaldo, A.B. (2020) Taxonomic Revision of the Spider Genus Actinopus Perty, 1833 (Araneae, Mygalomorphae, Actinopodidae). Megataxa, 2, 1-255. https://doi.org/10.11646/megataxa.2.1.1

Muñoz-Rodríguez P, Carruthers T, Wood JR, Williams BR, Weitemier K, Kronmiller B, Goodwin Z, Sumadijaya A, Anglin NL, Filer D, Harris D, Rausher MD, Kelly S, Liston A, Scotland RW (2019) A taxonomic monograph of Ipomoea integrated across phylogenetic scales. Nature Plants, 5(11), $1136-1144$.

https://doi.org/10.1038/s41477-019-0535-4

Zhang, Z.-Q. (2020) Megataxa for big science questions in taxonomy. Megataxa, 1 (1), 1-3.

https://doi.org/10.11646/megataxa.1.1.1 